\title{
Public Transport Policy Measures for Improving Elderly Mobility
}

\author{
R.C.P. WONG, W.Y. SZETO*, Linchuan YANG, Y.C. LI and S.C. WONG \\ Department of Civil Engineering, The University of Hong Kong, Hong Kong \\ *Corresponding Author, E-mail: ceszeto@hku.hk \\ Phone: (852) 28578552 \\ Fax: (852) 25595337
}

\begin{abstract}
Population aging is happening in most of the world's metropolitan cities, and the proportion of elderly adults is predicted to increase significantly in the coming decades. This rapid growth of elderly populations may lead to serious transport issues when their mobility is compromised by the unavailability of public transport services. Public transport concession fare schemes are commonly implemented in many cities to encourage the elderly's participation in social activities. However, these policies emphasize the role of money (i.e., travel fares) in determining willingness to travel. Other possible factors, such as walking distance to and from stops and stations, wait times for public transport services, and seat availability, have not been considered by transport operators and policy makers. In this study, we interviewed 613 elderly Hong Kong residents aged 60 or above regarding their travel decisions using designated modes of public transport to attend social activities in four hypothetical games. A total of 2,452 observations were collected for model development. Binary logistic regression models were calibrated to determine which factors significantly influenced the elderly's travel decisions. Based on the model results, this paper suggests policy measures to strengthen public transport planning in Hong Kong with the goal of improving elderly mobility. The findings provide policy insights that can also be applied to other metropolitan cities with similar traffic conditions.
\end{abstract}

Keywords: Public transport; Elderly mobility; Binary logistic regression model; Public transport concession fare schemes; Priority seats

\section{Introduction}

\subsection{Ageing population}

Population aging has become a notable, pervasive, and enduring demographic phenomenon in most countries. The proportion of populations aged 60 and over is growing steadily and vigorously, faster than any other age group. According to the forecast issued by the World Health Organization (2002), there will be two billion elderly adults by 2050, constituting an even larger share of society. This anticipated rapid growth in the elderly population poses a great challenge for transport operators, managers, and urban planners tasked with offering travel options that consider the unique and complex travel patterns of the elderly (Alsnih and Hensher, 2003; Hess, 2009). The challenges aging poses for the economy, health care, and retirement systems have been long recognized. However, the impact of aging on the transport system has been discovered much more recently and has not been extensively addressed (Buehler and Nobis, 2010).

Predominantly due to sustained low fertility and mortality rates, the population in Hong Kong is aging at an unprecedented rate. In 2015, the proportion of people aged 60 and above was the second highest in Asia, exceeded only by that in Japan (United Nations, 2015). According to population projection data for 2015-2064, the proportion of elderly people aged 60 and above in the Hong Kong population is expected to reach 38.0\% in 2064 (Census and 
Statistics Department, 2015). Indeed, Hong Kong's ageing population has already created numerous social and economic challenges, such as health care, the old age allowance, and senior residence provisions (Financial Services and the Treasury Bureau, 2013). Unfortunately, the effects of ageing populations on transport systems have been largely ignored by government officials and policy makers, such that the existing transport system is inadequate to support the striking increase in the elderly population in the near future. There is no doubt that improvements in elderly mobility facilitate the promotion of overall societal development, especially in the transport sector (Olawole and Aloba, 2014). Therefore, such improvements should be a top priority for transport policy makers.

\subsection{Elderly mobility issues}

Mobility refers to a person's ability to move from one place to another in an independent and safe way, and it typically declines gradually as people age (Rantakokko et al., 2013). For the elderly, mobility is not only a crucial element of overall life satisfaction but also a prerequisite for active aging. It is essential for independence and ensuring good health and quality of life (Whelan et al., 2006; Tacken, 1998; Metz, 2000; Banister and Bowling, 2004; Spinney et al., 2009). A lack of mobility can deter older people from participating in social activities, resulting in low morale, depression, and loneliness (Atkins, 2001). With the deficits in their sensory function and musculoskeletal strength, the elderly are a disadvantaged group that requires special attention (Ipingbemi, 2010). Therefore, it is vital to maintain the mobility of elderly people to ensure that they can continue to engage in civic and social life, take part in community activities, and pursue human interactions that enrich their health, wellbeing, and quality of life from a social integration perspective (Dickerson et al., 2007). Thus, future transport policies should prioritize the mobility of elderly populations to support their independence and thereby improve their quality of life.

Improving elderly mobility should be regarded as an important part of promoting overall societal development, especially in the transport sector (Olawole and Aloba, 2014). Maintaining the quality of elderly people's daily lives by improving their mobility should be a top priority for transport policy makers. In most Western countries, for example in the United States, driving is the most common mode of transport among elderly, and only a small portion of them use public transport (Ritter et al., 2002). The key reasons contributing to the infrequent use of public transport by older Americans, include (1) unreliable public transport services; (2) difficulties in accessing bus stops/stations and transfers; (3) an unavailability of some destinations; and (4) fear of crime (Burkhardt at el., 2002). From the statistics of bus crime in Los Angeles, it is found that the elderly are more likely to be victimized than other subpopulations and their fear of personal security significantly affects their frequency of bus use (Levine and Wachs, 1986). Some other potential factors may also adversely affect ridership for the old adults, including fears for safety (falling or being hit), and concerns about becoming disoriented or lost. Accordingly, numerous studies have been conducted on the driving behavior and safety of elderly drivers (Stamatiadis et al., 1991; Robertson and Aultman-Hall, 2001; Yannis et al., 2010; Broberg and Willstrand, 2014; Nakagawa et al., 2013; Gelau et al., 2011). Some other studies have also been conducted on the travel patterns of the elderly (Wachs, 1979; Carp, 1988; Hildebrand, 2003; Newbold et al., 2005; Schmöcker et al., 2008; Buehler and Nobis, 2010; Broome et al., 2012; Siren and Haustein, 2013) in an effort to improve their mobility. However, the majority of pertinent studies have been focused on car-dominant cities that are vastly different from transit-oriented cities.

In contrast with car-dominant cities, transit-oriented cities (e.g., Hong Kong, Singapore, and London) have a well-developed and sophisticated transport network and provide more frequent and relatively reliable public transport services (Land Transport 
Authority, 2012). In Hong Kong, only 14.4\% households own a private car, and about 93.0\% of the labor force uses public transit for their daily commutes (Transport Department, 2014). The transit shares of the elderly aged 60-69, 70-79, 80 and above are 93.6\%, 95.5\%, and $96.5 \%$, respectively (Szeto et al., 2017a). The figures indicate that the elderly are regarded as a less privileged population segment with limited transport choices, and their mobility is very dependent on public transport, particularly of those retired and older. It is therefore believed that the results obtained from car-dominated cities cannot be directly applied to transitoriented cities. There is a need to identify the factors that significantly influence the elderly's travel decisions of using public transport services in a high density and transit-oriented city so as to propose public transport policy measures for improving elderly mobility in that city.

\subsection{Public transport policy measures}

To improve elderly mobility, the Hong Kong government's transport policies, planning, and regulations have introduced the vision of "Transport for All" and have emphasized creating systems that are accessible to the elderly. Public transport concession fare schemes have been implemented in some public transport modes (including railways, buses, and ferries in the first stage of the implementation and public light buses in the second (and current) stage) to subsidize the elderly by traveling any time for a concession fare of HK\$2 per trip. (Buses operating in Hong Kong are usually double-decker buses with a maximum capacity of 146 passengers; public light buses carry a maximum of 16 seated passengers and mainly serve as feeder services). However, the schemes emphasize the role of money (i.e., travel fares) in determining willingness to travel, and does not consider some other potentially influential factors that may adversely affect the elderly's preference of using public transit. Hong Kong is one of the safest nations or cities in the world with a very low crime rate. The number of crimes about thief from vehicle in 2016 is 876, consisting of less than $1.5 \%$ of the overall crime (Hong Kong Police Force, 2016). Hence, personal security is not the most pressing mobility problem for the elderly residents. According to the latest research about elderly's satisfaction with the public transport services (Wong et al., 2017), the service aspects demanding immediate improvement, include (1) driver's attitude, (2) the condition of stops and stations, and (3) seat availability. Although, priority seats for people with special needs are recently provided on railways and buses to encourage the elderly to travel by these public transport modes and participate more in social activities, the elderly often have to stand because priority seats are limited and occupied by other passengers (Department of Applied Social Sciences, 2015), which adversely affects their willingness to travel.

\subsection{Research objectives, contributions, and paper outline}

To establish policy measures effectively enhancing elderly mobility, a comprehensive study is essential and necessary. In this study, we conducted a stated preference survey in which we interviewed 613 elderly residents aged 60 or above and asked them to indicate whether they would rather make a trip by a designated public transport mode or stay home in four hypothetical scenarios. A total of 2,452 observations were collected to develop binary logistic regression models for identifying possible factors that significantly influence the elderly's travel decisions of using public transport services in a high density and transitoriented city. It is worth emphasizing that the proportion of elderly using public transit is already very high (over 90\%) in Hong Kong. The key objective of improving the existing services to the elderly is not to get the final $10 \%$ into public transit options. The challenges and thus the research questions are how to enhance the elderly mobility to make more trips 
and what are the factors influencing their travel decision of making or not making a trip to participate in social activities. This study aims to address these questions.

This study makes several contributions, including the following:

- It fills the research gap and provides an empirical analysis of elderly mobility in Hong Kong, a transit-oriented and high-density city;

- It identifies the factors that significantly influence the elderly's travel decisions of using public transport services in a transit-oriented and high-density city; and

- It suggests policy measures to strengthen public transport planning in Hong Kong, with the goal of improving elderly mobility. The proposed measures can also be applied to other metropolitan cities with similar traffic conditions.

The remainder of this paper proceeds as follows. The next section describes the data collection method; tabulates the interviewed respondents' socio-demographical distribution, travel patterns, satisfaction with the existing public transport services and policy measures; and describes the stated preference survey. The subsequent two sections present model results and discuss potential policy measures. The last section concludes the paper and suggests research directions for future studies.

\section{Materials and Methods}

\subsection{Data collection}

An ethical approval was obtained from the University of Hong Kong prior to collecting data. Two pilot surveys were conducted in December 2014 and January 2015 to select the survey questions and verify their appropriateness. To ensure complete and thorough coverage of the study area and avoid any sampling bias, the main survey was conducted in March 2015 at numerous selected district elderly community centers, clinical centers, public housing estates, parks, and public transport stations in both the urban and rural areas of Hong Kong. These sites were typically frequented by the elderly. No special events or incidents occurred during the survey periods, which may potentially ruin the quality and reliability of the survey data. Our surveyors approached the potential respondents and obtained their verbal consent to participate in the survey before the survey was started. Our surveyors read the questions aloud, asked for their preference of making a trip or staying home in four hypothetical games, and filled in the questionnaires with only closed questions. It took around five minutes to complete one questionnaire. We successfully interviewed 613 elderly respondents and 2,452 observations were collected for model development.

\subsection{Socio-demographic characteristics}

The socio-demographic characteristics of the interviewed respondents are tabulated in Table 1 . The samples covered a broad spectrum of elderly adults, which were quite evenly distributed into five age and two gender cohorts. Most of them (92.5\%) had no full- or parttime job, without any compulsory commuting trips. $94.6 \%$ of the respondents' households did not own a private car and thus they had to rely on public transport services. Over $95 \%$ of the respondents had a monthly personal expenditure of less than HK\$10,000, which indicated that they could not afford a high transportation cost. More than half of the respondents lived with their spouse and/or children, whose family members could help them to do the out-of-home activities (e.g., shopping), and hence they might have less initiative of going out to participate in social activities. 
Table 1

Socio-demographic profiles.

\begin{tabular}{|c|c|c|}
\hline Personal Particulars & Group & $\begin{array}{c}\text { Frequency (Percentage) } \\
\text { [Sample Size }=613]\end{array}$ \\
\hline \multirow{5}{*}{ Age } & 60-64 years & $75(12.2 \%)$ \\
\hline & 65-69 years & $122(19.9 \%)$ \\
\hline & 70-74 years & $117(19.1 \%)$ \\
\hline & 75-79 years & $121(19.7 \%)$ \\
\hline & 80 years or above & $178(29.1 \%)$ \\
\hline \multirow{2}{*}{ Gender } & Male & $317(51.7 \%)$ \\
\hline & Female & $296(48.3 \%)$ \\
\hline \multirow{3}{*}{ Education } & Primary or below & $390(63.6 \%)$ \\
\hline & Secondary & $177(28.9 \%)$ \\
\hline & Tertiary & $46(7.5 \%)$ \\
\hline \multirow{4}{*}{ Occupation status } & Retired & $524(85.5 \%)$ \\
\hline & Homemaker & $43(7.0 \%)$ \\
\hline & Full-time job & $27(4.4 \%)$ \\
\hline & Part-time job & $19(3.1 \%)$ \\
\hline \multirow{2}{*}{$\begin{array}{l}\text { Car available for household } \\
\text { use }\end{array}$} & No & $580(94.6 \%)$ \\
\hline & Yes & $33(5.4 \%)$ \\
\hline \multirow{5}{*}{$\begin{array}{l}\text { Monthly personal } \\
\text { expenditure }\end{array}$} & HK $\$ 1,000$ or below & $42(7.0 \%)$ \\
\hline & HK\$1,001-5,000 & $422(68.8 \%)$ \\
\hline & HK\$5,001-10,000 & $124(20.2 \%)$ \\
\hline & HK\$10,001-15,000 & $19(3.1 \%)$ \\
\hline & HK $\$ 15,001$ or above & $5(0.8 \%)$ \\
\hline \multirow{8}{*}{$\begin{array}{l}\text { Household } \\
\text { (Respondents could } \\
\text { provide multiple answers) }\end{array}$} & Living alone & $110(17.9 \%)$ \\
\hline & Living with spouse & $335(54.7 \%)$ \\
\hline & Living with parents & $5(0.8 \%)$ \\
\hline & Living with children & $327(53.3 \%)$ \\
\hline & Living with grandchildren & $55(9.0 \%)$ \\
\hline & Living with other relatives & $5(0.8 \%)$ \\
\hline & Living with friends & $7(1.1 \%)$ \\
\hline & Others (e.g., elderly home) & $19(3.1 \%)$ \\
\hline
\end{tabular}

\subsection{Travel patterns}

Table 2 presents the elderly respondents' travel patterns and the effects of the current public transport policy measures on their travel decisions. After the implementation of public transport fare concession schemes and provision of priority seats, up to $70 \%$ of the respondents were satisfied with the public transport. However, large percentages of them (71.5\% and $86.1 \%$ ) did not increase their intention to travel. This phenomenon seems to imply that the current public transport policy measures helped improve their satisfaction level but not effectively enhance their mobility. Perhaps, the measures had already successfully maintained their public transport use and social activity participation. As referred to the experience in Queensland (Broome et al., 2013), the implementation of age-friendly guidelines for public buses resulted in improved satisfaction with the bus system and prevented declining in ease of bus use. 
Table 2

Travel patterns and feedback on public transport policy measures.

\begin{tabular}{|c|c|c|}
\hline Travel Patterns/ Comments & Group & $\begin{array}{l}\text { Frequency (Percentage) } \\
\text { [Sample Size }=613]\end{array}$ \\
\hline \multirow{5}{*}{$\begin{array}{l}\text { Frequency (number of } \\
\text { days) of using public } \\
\text { transport service in a week }\end{array}$} & Less than 1 & $135(22.0 \%)$ \\
\hline & $1-2$ & $182(29.7 \%)$ \\
\hline & $3-4$ & $115(18.8 \%)$ \\
\hline & $5-6$ & $29(4.7 \%)$ \\
\hline & Every day & $152(24.8 \%)$ \\
\hline \multirow{7}{*}{$\begin{array}{l}\text { Trip purpose } \\
\text { (Respondents could } \\
\text { provide multiple answers) }\end{array}$} & Medical appointment & $99(16.2 \%)$ \\
\hline & Visit friends and relatives & $205(33.4 \%)$ \\
\hline & Shopping & $171(27.9 \%)$ \\
\hline & Social activities & $27(4.4 \%)$ \\
\hline & Go for a walk & $176(28.7 \%)$ \\
\hline & Leisure activities & $205(33.4 \%)$ \\
\hline & Others & $114(18.6 \%)$ \\
\hline \multirow{3}{*}{$\begin{array}{l}\text { Overall satisfaction with } \\
\text { public transport services }\end{array}$} & Dissatisfied & $33(5.4 \%)$ \\
\hline & Neutral & $151(24.6 \%)$ \\
\hline & Satisfied & $429(70.0 \%)$ \\
\hline \multirow{3}{*}{$\begin{array}{l}\text { Deliberate travel using } \\
\text { discounted public transport } \\
\text { modes }\end{array}$} & Yes & $192(31.3 \%)$ \\
\hline & No & $353(57.6 \%)$ \\
\hline & Depends & $68(11.1 \%)$ \\
\hline \multirow{3}{*}{$\begin{array}{l}\text { More willing to travel after } \\
\text { implementation of } \\
\text { concession fare schemes }\end{array}$} & No & $438(71.5 \%)$ \\
\hline & Yes, a little more & $108(17.6 \%)$ \\
\hline & Yes, a lot more & $67(10.9 \%)$ \\
\hline \multirow{3}{*}{$\begin{array}{l}\text { More willing to travel after } \\
\text { provision of priority seats }\end{array}$} & No & $528(86.1 \%)$ \\
\hline & Yes, a little more & $79(12.9 \%)$ \\
\hline & Yes, a lot more & $6(1.0 \%)$ \\
\hline
\end{tabular}

During the interviews, most of the respondents expressed concerns about the provision of priority seats. They recommended increasing the number of priority seats and boosting awareness of the importance of offering priority seats to people in need among regular passengers. They also requested more frequent services to shorten wait times, and better waiting areas at railway stations and bus/public light bus stops. Some of the respondents requested that the government should extend the coverage to include public transport fare concession schemes for people aged 60-64. (Some bus service providers were providing discounts to their passengers in this age group.)

\subsection{Stated preference survey}

In this study, the interviewed old adults were asked to select a preferable choice among two alternatives (making a trip by a designated public transport mode for a noncompulsory social activity and staying home) in four hypothetical games. According to our observations in the pilot surveys, the elderly respondents had difficulties of making decisions when too many factors and subjective factors (e.g., driver's attribute, and level of comfort) were included in the stated preference survey. Therefore, we simplified the questions and only included four modes of transport and three quantitative variables. Binary logistic regression models were then calibrated to determine the model coefficient associated with each explanatory variable. This modeling approach has been commonly used to study choice 
decisions of individuals from two alternatives based on utility maximization in the context of transport behavioral studies (e.g., Marquet and Miralles-Guasch, 2016; Ko and Kim, 2017; Le Vine and Polak, 2017; Szeto et al., 2017b). The binary logistic regression model is chosen in this study because this model can address the research objective on identifying the explanatory variables that influence the old adults' travel decision of making or not making a trip to participate in social activities. If a variable in the proposed model is associated with a positive coefficient, it implies that the variable has a positive effect on the probability of making a trip. This probability increases with the value of this variable. Conversely, if a variable has a negative coefficient, the variable adversely influences the probability of making a trip. The respondents' travel decisions of using public transport services were considered to be influenced by the following explanatory variables.

Mode of public transport: Different modes of public transport provide dissimilar travel experiences to the elderly, which potentially affects their willingness to travel. This variable describes the respondents' general perceptions of different transport modes in terms of their reliability, travel stability, and level of comfort, etc. According to the travel pattern of elderly residents in Hong Kong (Szeto et al., 2017a), they preferred traveling by buses and railways because of their reliable and convenient services. On the other hand, the rough and uncomfortable rides provided by public light buses and the high travel cost of using taxis were the reasons of the elderly less preferable to using these modes, even though seats are guaranteed and walking distances are usually shorter.

Travel fares: It is expected that most of the elderly residents aged 60 or above were unemployed or retired with a limited monthly personal expenditure and cannot afford a high transportation cost. Expensive travel fares may be a financial burden for them, which would decrease their willingness to travel by the particular transport modes. The public transport concession fare schemes entirely waiving their travel costs effectively enhanced elderly mobility according to the experience in Britain (Baker and White, 2010).

Walking and wait times: Most of the public transport modes (except taxis) offer stop-to-stop services. Walking and wait times for public transport services can always be used to describe the difficulty in getting the elderly from their trip origins to transport hubs, such as railway stations and bus/public light bus stops. Due to the deficits in the sensory function and musculoskeletal strength of the elderly, it is difficult for them to walk for a long time. Moreover, the conditions of stations and stops (e.g., provisions of seats and shelters) are not age-friendly and favorable to the elderly (Wong et al., 2017). They may have to stand and wait for public transport services under direct sunlight and rain. This results in a very uncomfortable condition for the elderly waiting at stops and stations. Improving the accessibility of public transport services may help increase their willingness to travel.

Seat availability: Long-term standing inside a moving vehicle is already hard for the elderly particularly of those with poor physical health. If the journey is rough and unstable, the elderly passengers may even fall and suffer an injury. Although priority seats are provided on railways and buses, the elderly have relayed that the provision of priority seats is inadequate (Department of Applied Social Sciences, 2015) and they always need to stand because other passengers refuse to offer their seats. Thus, providing them dedicated seats is extraordinarily important in improving elderly mobility.

A fractional factorial design was adopted in this study to reduce the sizes of experiments and make effective use of resources. We generated 36 combinations of hypothetical games involving the above four explanatory variables and randomly distributed into nine sets of questionnaire. Four most popular modes of public transport were studied. Both the travel fare and walking and wait times were designed as 3-level factors for capturing nonlinear effects. For seat availability, because seats are guaranteed in public light buses and taxis, the possibility of having no seat was neglected. Table 3 shows the attributes and levels 
used in the stated preference survey. The respondents were asked to decide between going out to attend a non-compulsory social activity by a given mode of public transport and staying home. A combined all-four-mode model was first developed to obtain the overall perceptions of the elderly on the three quantitative variables and four mode-specific models were then developed to understand how the variables contribute to the trip-making decision of each mode and to lead to more targeted policy directions.

Table 3

Attributes and levels used in the stated preference survey.

\begin{tabular}{|c|c|c|c|c|c|}
\hline \multirow{2}{*}{ Games } & $\begin{array}{c}\text { Modes of } \\
\text { Public } \\
\text { Transport }\end{array}$ & $\begin{array}{c}\text { Travel Fare } \\
\text { (HK\$) }\end{array}$ & $\begin{array}{c}\text { Walking and Wait } \\
\text { Times (min) }\end{array}$ & $\begin{array}{c}\text { Seat } \\
\text { Availability }\end{array}$ & \multirow{2}{*}{ Choices } \\
\hline 1 & Railways & $0,2,4$ & $5,8,11$ & $\begin{array}{c}1 \text { (Yes), } \\
0(\text { No) }\end{array}$ & \\
\hline 2 & Buses & $0,2,4$ & $6,10,14$ & $\begin{array}{c}1 \text { (Yes), } \\
\text { (No) }\end{array}$ & $\begin{array}{c}\text { 1 (Going out), } \\
\text { (Staying } \\
\text { home) }\end{array}$ \\
\hline 3 & $\begin{array}{c}\text { Public light } \\
\text { buses }\end{array}$ & $2,4,6$ & $6,10,14$ & $\begin{array}{c}1 \text { (Seat } \\
\text { guaranteed) }\end{array}$ & $\begin{array}{c}1 \text { (Seat } \\
\text { guaranteed) }\end{array}$ \\
\hline 4 & Taxis & $15,20,25$ & $4,7,10$ & \\
\hline
\end{tabular}

In addition to the above-mentioned explanatory variables, it is anticipated that respondents with different socio-demographic characteristics may make substantially different choices of making a trip. An extended model was calibrated by incorporating the socioeconomic factors to study the heterogeneity of travel decisions for the respondents with different backgrounds.

\section{Results}

A data analysis and statistical software package STATA was used with the maximum likelihood estimation method to calculate the coefficient associated with each variable, based on the 2,452 observations. Table 4 tabulates the results of the combined all-four-mode model and mode-specific models. All the explanatory variables in the combined all-four-mode model are significant at the $1 \%$ level. The coefficient signs are reasonable and meet our expectations, which imply that higher travel fare and longer walking and wait times adversely influence elderly's willingness to travel. Conversely, the provision of seats effectively increases their probability of making a trip.

For the mode-specific models, it is noticed that both the travel fare and seat availability are important for the elderly individuals traveling by railways and buses. Comparatively, the magnitude of the coefficient associated with seat availability for buses is about three times of that for railways. It suggests that providing sufficient priority seats in buses can more effectively enhance the elderly's probability of making a trip, probably due to the less stable journey of buses. Since seats are guaranteed in public light buses and taxis, the explanatory variable of seat availability is excluded in the corresponding models. For the model associated with public light buses, the absolute value of the coefficient associated with travel fare is the highest among all the public transport modes and it is about three times of the average value as calibrated in the combined all-four-mode model. It implies that reducing the travel cost can significantly increase the ridership of this transport mode. The findings support the recent extension of the public transport concession fare schemes to subsidize the elderly for using public light buses. It is noted that all the three explanatory variables for the model 
associated with taxis were found insignificant, except the model constant which includes some other uncaptured influential factors. Taxi fare might be too high in both the reality and all three hypothetical scenarios for the elderly respondents, which led to its insensitivity to affect their travel decision. The negative coefficient associated with the model constant indicates that the elderly had a negative perception on taxi services and preferred not taking taxis for non-compulsory trips. They complained that taxi drivers were sometimes in haste and did not pay special attention to the elderly passengers.

\section{Table 4}

The results of the combined all-four-mode model and mode-specific models.

\begin{tabular}{|c|c|c|c|c|c|}
\hline \multirow[b]{2}{*}{$\begin{array}{c}\text { Explanatory } \\
\text { Variables }\end{array}$} & \multicolumn{5}{|c|}{ Coefficient (t-statistics) } \\
\hline & $\begin{array}{l}\text { Combined all- } \\
\text { four-mode }\end{array}$ & Railways & Buses & $\begin{array}{c}\text { Public light } \\
\text { buses }\end{array}$ & Taxis \\
\hline Travel fare & $-0.11^{\mathrm{a}}(-14.7)$ & $-0.11^{\mathrm{b}}(-2.2)$ & $-0.09^{\mathrm{C}}(-1.8)$ & $-0.29^{a}(-5.5)$ & $-0.02(-0.9)$ \\
\hline $\begin{array}{l}\text { Walking and } \\
\text { wait times }\end{array}$ & $-0.07^{\mathrm{a}}(-4.5)$ & $-0.01(-0.3)$ & $-0.06(-1.2)$ & $-0.01(-0.3)$ & $-0.01(-0.2)$ \\
\hline Seat availability & $0.39^{\mathrm{a}}(3.6)$ & $0.42^{\mathrm{b}}(2.4)$ & $1.11^{\mathrm{a}}(3.8)$ & -- & -- \\
\hline Constant & $0.57^{\mathrm{a}}(3.1)$ & $0.27(0.8)$ & $0.22(0.4)$ & $0.75^{\mathrm{b}}(2.2)$ & $-1.04^{\mathrm{C}}(-1.7)$ \\
\hline
\end{tabular}

Table 5 shows the results of the extended model with the variables for public transport mode characteristics and socio-economic factors. Regarding the modes of public transport, the coefficients associated with public light buses and taxis are negative. This implies that the respondents were less likely to travel using public light buses and taxis than buses if other variables were the same, which is intuitive and representative of reality. By comparing the coefficients of the three modes, we can see that the attractiveness of public light buses is the lowest, probably due to the rough and uncomfortable rides (Wong et al., 2017). In contrast, the coefficient associated with railways is not significant. There is no sufficient evidence showing that the respondents significantly preferred railways to buses.

The coefficients associated with both travel fare and walking and wait times are negative, implying that the respondents preferred to travel more when a public transport mode with a lower travel fare and a shorter time is offered. In contrast, the coefficient associated with seat availability is positive, implying that the respondents preferred to travel by modes with guaranteed seat availability. The absolute value of its coefficient is much larger than that of the other two introduced above. Improving this aspect can more effectively improve elderly mobility. The value of walking and wait times is about HK\$0.4 per minute, which is derived from the absolute value of the corresponding coefficient of walking and wait times $(-0.03)$ over that of travel fare (-0.08). Likewise, the value of seat availability is HK\$10.5, which equals the absolute value of the associated coefficient of seat availability (0.84) dividing by that of travel fare $(-0.08)$.

Various socio-economic factors were incorporated into the model for analysis. Regarding different age groups, the coefficients of 70-74 years, 75-79 years, and 80 years or over are all significant at the 5\% level, and their values decrease as the age increases. This shows that mobility declines gradually as people age (Rantakokko et al., 2013). The female respondents in a multiple-person household traveled significantly less than their male counterparts, perhaps because women were responsible for housework in a multi-person household and thus they make fewer trips than men in their families (Szeto et al., 2017a). This is largely consistent with other gender travel studies (Su and Bell, 2012). The respondents with a higher personal monthly expenditure were more likely to go out. They were more 
economically active and thus could travel without any financial burden. The coefficient associated with the household structure is positive and significant at the $10 \%$ level, suggesting that the elderly who live with others have a higher tendency to stay home, which concurs with our discussion in Section 2.2. Elderly individuals who lived alone must go out to shop and support their daily lives all by themselves with no one to share the work load. However, we may have unconsciously excluded many elderly individuals who lived alone and always stayed home. Home-based interviews are recommended to be conducted in future research to address the limitations of this study. Actual frequent public transport users in the reality were more likely to select "going out for a non-compulsory social activity" in hypothetical games (1\% significance). The variables for having a full- or part-time job and being satisfied with public transport services have a positive influence on willingness to travel but are only significant at the $10 \%$ level. We recommend obtaining a larger sample size in future research to verify the importance of these variables. The constant term is modest at 0.44 , which means that the proposed binary logistic regression can effectively model the travel behavior of the elderly with limited uncaptured factors.

\section{Table 5}

The results of the combined all-four-mode model with the variables for public transport mode characteristics and socio-economic factors.

\begin{tabular}{|c|c|c|c|}
\hline Explanatory Variables & Group & Control & Coefficient (t-statistics) \\
\hline \multirow{3}{*}{ Modes of public transport } & Railways & \multirow{3}{*}{ Buses } & $0.09(0.7)$ \\
\hline & Public light buses & & $-0.76^{\mathrm{a}}(-5.2)$ \\
\hline & Taxis & & $-0.72^{\mathrm{C}}(-1.9)$ \\
\hline \multirow{3}{*}{ Mode characteristics } & Travel fare & \multirow{3}{*}{--} & $-0.08^{\mathrm{a}}(-4.1)$ \\
\hline & $\begin{array}{l}\text { Walking and wait } \\
\text { times }\end{array}$ & & $-0.03^{\mathrm{C}}(-1.9)$ \\
\hline & Seat availability & & $0.84^{\mathrm{a}}(6.3)$ \\
\hline \multirow{3}{*}{ Age } & 70-74 years & \multirow{3}{*}{$60-69$ years } & $-0.32^{b}(-2.5)$ \\
\hline & 75-79 years & & $-0.34^{\mathrm{b}}(-2.5)$ \\
\hline & 80 years or above & & $-0.42^{\mathrm{a}}(-3.4)$ \\
\hline Gender & Female & Male & $-0.25^{\mathrm{a}}(-2.7)$ \\
\hline $\begin{array}{l}\text { Personal monthly } \\
\text { expenditure }\end{array}$ & $\begin{array}{l}\text { More than } \\
\text { HK } \$ 5,000\end{array}$ & $\begin{array}{l}\text { HK } \$ 5,000 \text { or } \\
\text { below }\end{array}$ & $0.20^{\mathrm{C}}(1.9)$ \\
\hline Household structure & Living alone & Not living alone & $0.21^{\mathrm{C}}(1.8)$ \\
\hline $\begin{array}{l}\text { Frequency (number of } \\
\text { days in a week) of taking } \\
\text { public transport }\end{array}$ & $\begin{array}{l}\text { Less than one day } \\
\text { in a week }\end{array}$ & $\begin{array}{l}\text { At least one day } \\
\text { in a week }\end{array}$ & $-0.75^{\mathrm{a}}(-6.3)$ \\
\hline Occupation status & $\begin{array}{l}\text { With full- } \\
\text { time/part-time job }\end{array}$ & Without job & $0.08(0.4)$ \\
\hline $\begin{array}{l}\text { Overall satisfaction with } \\
\text { public transport services }\end{array}$ & Satisfied & $\begin{array}{l}\text { Dissatisfied or } \\
\text { neutral }\end{array}$ & $0.13(1.4)$ \\
\hline \multicolumn{2}{|l|}{ Constant } & -- & $0.44^{\mathrm{b}}(1.8)$ \\
\hline
\end{tabular}

Note: ${ }^{\mathrm{a}}$ Parameters are significant at the $1 \%$ level. ${ }^{\mathrm{b}}$ Parameters are significant at the $5 \%$ level.

${ }^{\mathrm{c}}$ Parameters are significant at the $10 \%$ level.

The McFadden pseudo $\mathrm{R}^{2}$ is 0.085 for the combined all-four-mode model (as shown in Table 4), and it is improved to 0.122 for the model additionally considers the variables of public transport mode and socio-economic factors. In addition, the Nagelkerke $\mathrm{R}^{2}$ for these models 
are 0.146 and 0.205 , respectively, which suggests that the extended model has a slightly better model fit. Both the models are significant at the $0.1 \%$ level. Accordingly, the results demonstrate that the extended model with more explanatory variables is superior to the standard one, and is preferable to be chosen for suggesting policy measures.

\section{Discussion}

This study confirms that public transport modes, three concerned travel aspects, and numerous socio-demographic characteristics influence the travel decisions of the elderly in Hong Kong, a high-density and transit-oriented city. The attractiveness of railways and buses was higher than that of public light buses. Rough and uncomfortable journeys are particularly unfavorable among the elderly due to their poor physical condition (Wong et al., 2017). In the new era of population aging, travel stability should place a higher priority on improving public transport services.

The target beneficiaries of public transport fare concession schemes are the elderly individuals aged 65 years or older and eligible people with disabilities. Recently, more elderly individuals are retiring at the age of 60 but must pay full-price for public transport until the age of 65. As the respondents indicated in their face-to-face interviews, a scheme that subsidizes those aged 60-64 years with a discount (e.g., half-price), would improve their mobility. Such travel fare discounts would provide additional incentives for retired elderly individuals aged 60-64 to travel. In contrast, the calibrated model showed that the mobility of elderly individuals aged 80 or above was obviously lower. The public transport concession fare schemes may consider entirely waiving their travel costs to encourage participating in social activities, which had been proved effectively enhancing elderly mobility in Britain (Baker and White, 2010). Moreover, the schemes only cover four public transport modes (railways, buses, ferries, and public light buses). An extension to other modes is worth exploring. Given that these improvement measures may cause profit loss for the operators, subsidization from the government could be considered. The government should liaise with the public transport operators through the franchising process for setting general and concession fare levels, which was also pointed out by Rye and Carreno (2008) and Rye and Scotney (2004).

According to the model results, shortening the walking and wait times for public transport services can improve the probability of the elderly making a trip. This is because shortening walking and wait times can enhance passengers' travel experiences. It is considered that the accessibility of railway stations and bus/public light bus stops (represented by walking time) is extraordinarily important in determining elderly individuals' willingness to travel. Long walking time and poor walking conditions on routes to and from transport facilities may hinder elderly mobility (Loo and Lam, 2012; Somenahalli and Shipton, 2013). Moreover, the service frequency of public transport (represented by wait time) also affects elderly individuals' willingness to travel. According to the previous research using survey data from the Travel Characteristics Survey (Szeto et al., 2017a), elderly individuals concentrate their travel from 10 am to 11 am (traditional off-peak hours) to avoid crowds. However, the frequencies of most of the public transport modes are reduced during that window, which can lead to a longer wait time. Therefore, enhancing the accessibility of stations and stops and increasing service frequency should be investigated to attract more elderly to travel by public transport in the context of high-density and transit-oriented cities such as Hong Kong.

The model results also show that improving seat availability can more effectively enhance the elderly's probability of making a trip. Moreover, seat availability poses the highest priority for improvement with a large proportion of the elderly considered this service 
aspect either dissatisfied or very dissatisfied (Wong et. al., 2017). The proportion of priority seats on each public transport mode should be increased to cater to the forthcoming aging trend, improve the elderly's satisfaction with public transport service, and enhance elderly mobility. Moreover, the culture and behavior of offering seats to the needy (the elderly, the disabled, pregnant women, and other people in need) should also be strongly promoted and encouraged. For example, a priority seat campaign could be launched by the government or mass transit operators. Furthermore, the policy-makers may also consider the introduction of a Priority Seat card or badge, as has been a custom in London since 2012, to provide a clear indicator that encourages other passengers to give up their priority seats for the needy.

\section{Conclusions}

Hong Kong and other metropolitan cities are facing a serious aging problem, with the population of elderly continuing to increase in the forthcoming years. Future transport policies should prioritize improving the mobility of elderly individuals, supporting their independence, and thereby enhancing the quality of their lives. Public transport concession fare schemes have been implemented to encourage more elderly to use related transport services. However, the policies place too much emphasis on the role of money (i.e., travel fares) in determining willingness to travel; other factors, such as walking and wait times and seat availability, have been not considered by transit operators and policy makers. In this study, 2,452 observations were collected from 613 elderly residents about their willingness to travel for a noncompulsory social activity during face-to-face interviews. Binary logistic regression models were then calibrated for possible influential factors.

The developed models show that public transport modes, travel fare, walking and wait times, seat availability, and numerous socio-economic factors are key factors that influence travel decisions among the elderly. Railways and buses are more attractive modes of travel than public light buses and taxis. The magnitude of the coefficient associated with seat availability is the highest among all the variables of mode characteristics, which implies that seat availability poses the top priority for enhancement to improve elderly mobility.

Based on the model results, we suggest increasing the provision of priority seats to address the forthcoming aging trend. We also recommend extending the coverage of the target beneficiaries of public transport fare concession schemes to include those aged 60-64 and waiving the travel costs to the elderly aged 80 or above to encourage their participation in social activities. Moreover, ways to enhance the accessibility of stations and stops and increase service frequency should be investigated to attract more elderly to travel by public transport in the context of high-density and transit-oriented cities such as Hong Kong.

This study has a few limitations that merit further research. First, we only covered four popular public transport modes. Including more options (e.g., light railways and tramways) would be beneficial to reflect a broader spectrum of transit systems in Hong Kong. Second, developing a multinomial logistic regression model to study the modal split of the elderly can provide more policy insights in further enhancing their mobility. Third, as mentioned before, we may have unconsciously excluded many elderly individuals who lived alone and always stayed home. Home-based interviews are recommended to be conducted in future research to address this issue. Finally, the variables for having a full- or part-time job and being satisfied with public transport services are only significant at the $10 \%$ level. Obtaining a larger sample size in future research is recommended to verify the importance of these variables. 


\section{Acknowledgments}

This research was supported by a grant from the Central Policy Unit of the Hong Kong Special Administrative Region Government, Public Policy Research Funding Scheme (Project No.: 2014.A8.025.15B). The authors wish to thank Jenny Hoi Ki CHIONG, a student of the Civil Engineering Department, The University of Hong Kong, for her assistance with the data collection and analysis. The authors are grateful to the three reviewers for their constructive comments.

\section{References}

Alsnih, R., Hensher, D.A. 2003. The mobility and accessibility expectations of seniors in an aging population. Transport Research Part A: Policy and Practice 37(10), 903-916.

Atkins, W. 2001. Older people: Their Transport Needs and Requirements. Department of the Environment, Transport and the Regions.

Baker, S., White, P. 2010. Impacts of free concessionary travel: Case study of an English rural region. Transport Policy 17, 20-26.

Banister, D., Bowling, A. 2004. Quality of life for the elderly: The transport dimension. Transport Policy 11(2), 105-115.

Buehler, R., Nobis, C. 2010. Travel behavior in aging societies: Comparison of Germany and the United States. Transportation Research Record: Journal of the Transportation Research Board 2182, 62-70.

Burkhardt, J., McGravock, A., Nelson, C. 2002. Improving Public Transit Options for Older Persons. Technical Report Transit Cooperative Research Program Report No. 82, Transportation Research Board, Washington, D.C., United States.

Broberg, T., Willstrand, T.D. 2014. Safe mobility for elderly drivers: Considerations based on expert and self-assessment. Accident Analysis and Prevention 66, 104-113.

Broome, K., Worrall, L., Fleming, J., Boldy, D. 2013. Evaluation of age-friendly guidelines for public buses. Transportation Research Part A: Policy and Practice 53, 68-80.

Broome, K., Worrall, L., Fleming, J., Boldy, D. 2012. Evaluation of flexible route bus transport for older people. Transport Policy 21, 85-91.

Buehler, R., Nobis, C. 2010. Travel behavior in aging societies. Transport Research Record: Journal of the Transport Research Board 2182, 62-70.

Carp, F.M. 1988. Significance of mobility for the well-being of the elderly. In Transport in An Aging Society: Improving Mobility and Safety of Older Persons, 2, Washington, D.C., National Academy Press.

Census and Statistics Department. 2015. Hong Kong Population Projections 2015-2064. The Government of the Hong Kong Special Administrative Region.

Department of Applied Social Sciences, The Hong Kong Polytechnic University, 2015. Offering seats habits reviewed from a public opinion workshop.

Dickerson, A.E., Molnar, L.J., Eby, D.W., Adler, G., Bedard, M., Berg-Weger, M., Classen, S., Foley, D., Horowitz, A., Kerschner, H. 2007. Transport and aging: A research agenda for advancing safe mobility. The Gerontologist 47(5), 578-590.

Financial Services and the Treasury Bureau, 2015. The 2013-14 Budget. The Government of the Hong Kong Special Administrative Region.

Gelau, C., Sirek, J., Dahmen-Zimmer, K. 2011. Effects of time pressure on left-turn decisions of elderly drivers in a fixed-base driving simulator. Transport Research Part F: Traffic Psychology and Behaviour 14, 76-86.

Hess, D.B. 2009. Access to public transit and its influence on ridership for older adults in two US cities. Journal of Transport and Land Use 2(1), 3-27. 
Hong Kong Police Force. 2016. Crime Statistics 2015-2016. The Government of the Hong Kong Special Administrative Region.

Hildebrand, E.D. 2003. Dimensions in elderly travel behaviour: A simplified activity-based model using lifestyle clusters. Transport 30(3), 285-306.

Ipingbemi, O. 2010. Travel characteristics and mobility constraints of the elderly in Ibadan, Nigeria. Journal of Transport Geography 18(2), 285-291.

Iseki, H., Taylor, B.D. 2009. Not all transfers are created equal: Towards a framework relating transfer connectivity to travel behaviour. Transport Reviews 29(6), 777-800.

Ko, J., Kim, D. 2017. Employer-based travel demand management program: Employer's choice and effectiveness. Transport Policy 59, 1-9.

Land Transport Authority, Singapore, 2012. Key Transport Statistics of World Cities.

Le Vine, S., Polak, J. 2017. The impact of free-floating carsharing on car ownership: Earlystage findings from London. Transport Policy, in press.

Levine, N., Wachs, M. 1986. Bus crime in Los Angeles: II-Victims and public impact. Transportation Research Part A: General 20(4), 285-293.

Loo, B.P.Y., Lam, W.W.Y. 2012. Geographic accessibility around health care facilities for elderly residents in Hong Kong: A microscale walkability assessment. Environment and Planning B: Planning and Design 39(4), 629-646.

Marquet, O., Miralles-Guasch, C. 2016. City of motorcycles. On how objective and subjective factors are behind the rise of two-wheeled mobility in Barcelona. Transport Policy 52, 37-45.

Metz, D.H. 2000. Mobility of older people and their quality of life. Transport Policy 7(2), 149-152.

Nakagawa, Y., Park, K., Kuagai, Y. 2013. Elderly drivers' everyday behavior as a predictor of crash involvement: Questionnaire responses by drivers' family members. Accident Analysis and Prevention 50, 397-404.

Newbold, K.B., Scott, D.M., Spinney, J.E.L., Kanaroglou, P., Páez, A. 2005. Travel behavior within Canada's older population: A cohort analysis. Journal of Transport Geography 13(4), 340-351.

Olawole, M.O., Aloba, O. 2014. Mobility characteristics of the elderly and their associated level of satisfaction with transport services in Osogbo, Southwestern Nigeria. Transport Policy 35, 105-116.

Rantakokko, M., Mänty, M., Rantanen, T. 2013. Mobility decline in old age. Exercise and Sport Sciences Reviews 41(1), 19-25.

Robertson, S., Aultman-Hall, L. 2001. Impact of road conditions on elderly drivers. Journal of Transport Engineering 137(2), 244-246.

Ritter, A.S., Straight, A., Evans, E. 2002. Understanding Senior Transportation: Report and Analysis of a Survey of Consumers Age 50+. AARP Public Policy Institute, Washington, D.C., United States.

Rye, T., Carreno, M. 2008. Concessionary fares and bus operator reimbursement in Scotland and Wales: No better or no worse off? Transport Policy 15(4), 242-250.

Rye, T., Scotney, D. 2004. The factors influencing future concessionary bus patronage in Scotland and their implications for elsewhere. Transport Policy 11(2), 133-140.

Schmöcker, J.D., Quddus, M.A., Noland, R.B., Bell, M.G.H. 2008. Mode choice of older and disabled people: A case study of shopping trips in London. Journal of Transport Geography 16(4), 257-267.

Siren, A., Haustein, S. 2013. Baby boomers' mobility patterns and preferences: What are the implications for future transport? Transport Policy 29, 136-144.

Somenahalli, S., Shipton, M. 2013. Examining the distribution of the elderly and accessibility to essential services. Procedia-Social and Behavioral Sciences 104, 942-951. 
Spinney, J.E.L., Scott, D.M., Bruce Newbold, K. 2009. Transport mobility benefits and quality of life: A time-use perspective of elderly Canadians. Transport Policy 16(1), 111.

Stamatiadis, N., Taylor, W., McKelvey, F. 1991. Older drivers and intersection traffic control devices. Journal of Transport Engineering 177(3), 311-319.

Su, F., Bell, M.G.H. 2012. Travel differences by gender for older people in London. Research in Transport Economics 34(1), 35-38.

Szeto, W.Y., Yang, L., Wong, R.C.P., Li Y.C., Wong, S.C. 2017a. Spatial-temporal travel characteristics of the elderly in an aging society. Travel Behaviour and Society, under review.

Szeto, W.Y., Wong, R.C.P., Yang, W.H. 2017b. Guiding vacant taxi drivers to demand locations by taxi-calling signals: A sequential logistic modeling approach and policy implications. Transport Policy, under review.

Tacken, M. 1998. Mobility of the elderly in time and space in the Netherlands: An analysis of the Dutch national travel survey. Transport 25(4), 379-393.

Transport Department. 2014. Travel Characteristics Survey 2011 Final Report. The Government of the Hong Kong Special Administrative Region.

United Nations, 2015. World Population Ageing 2015. United Nations Publication, New York, United States.

Wachs, M. 1979. Transportation for the Elderly Changing Lifestyles, Changing Needs. Berkeley, United States: University of California Press.

Wardman, M. 2011. A review of British evidence on time and service quality valuations. Transport Research Part E: Logistics and Transport Review 37(2), 107-128.

Wentowski, G.J. 1981. Reciprocity and the coping strategies of older people: Cultural dimensions of network building. The Gerontologist 21(6), 600-609.

Whelan, M., Langford, J., Oxley, S., Koppel, J., Charlton, J. 2006. The Elderly and Mobility: A Review of the Literature. Monash University Accident Research Centre, Melbourne, Australia.

Wong, R.C.P., Szeto, W.Y., Yang, L., Li, Y.C., Wong, S.C. 2017. Elderly users' level of satisfaction with public transport services in a highly-density and transit oriented city. Journal of Transport \& Health, under review.

World Health Organization. 2002. Active Ageing: A Policy Framework. World Health Organization: Madrid, Spain.

Yannis, G., Antoniou, C., Vardaki, S., Kanellaidis, G. 2010. Older drivers’ perception and acceptance of in-vehicle devices for traffic safety and traffic efficiency. Journal of Transport Engineering 136, 472-479. 